were associated with DDI. The DDI incidence in the current study was lower than in the UK crash.

Prehosp Disaster Med 2011;26(Suppl. 1):s59-s60

doi:10.1017/S1049023X11002056

(A216) Ashmore Reef Boat Explosion: A Nightmare Scenario that Became a Reality

M.G. Leclercq, A.G. Robertson

Disaster Preparedness and Management Unit, East Perth, Australia

At approximately 06:15h on 16 April 2009, there was an explosion and subsequent fire onboard the Suspected Illegal Entry Vessel (SIEV) 36. The vessel was located in the vicinity of the Ashmore Reef, approximately 610 kilometers north of Broome in Western Australia (WA). Onboard were members of the Royal Australian Navy (RAN), 47 asylum seekers, and two crew members. Traveling with SIEV 36 were the RAN Patrol Boats, HMAS Childers, and HMAS Albany. The explosion resulted in five deaths and a large number of casualties with severe burn injuries, and a smaller number with concurrent trauma injuries. The Ashmore Reef incident was unique in that it involved the medical management and evacuation of 44 injured foreign nationals (31 seriously injured) in an extremely remote location. It resulted in an unprecedented health response from multiple agencies including local, regional, and state governments, commonwealth government agencies, non-government organizations, and private industry. The mission objective for this incident was to retrieve and evacuate multiple seriously injured casualties and stabilize them for safe transport to definitive care. The mission objective was achieved for the Ashmore Reef incident with no further deaths. As with all disasters, many lessons have been learned, and recommendations have been formulated. The logistic requirements to successfully complete such a mission have been reinforced as a result of this incident, as this was the most logistically challenging mass-casualty incident in WA history.

Prehosp Disaster Med 2011;26(Suppl. 1):s60

doi:10.1017/S1049023X11002068

(A217) Success Indicators of Emergency Medical Management: A Building Collapse Disaster

S. Satapathy, ${ }^{1}$ A. Banerjee, ${ }^{2}$ A. Babl $l^{3}$

1. PPCCI, 110002, India

2. Medical Superitendent, New Delhi, India

3. Accident \& Emergency, New Delhi, India

A four-story building collapse in east Delhi, India in November 2010 claimed 66 lives and left 130 injured. It is considered one of the worst such disasters in Delhi. This disaster included massive rescue operations to pull out those trapped under the debris. The nodal hospital, which did not have a well-defined hospital disaster management plan, managed the disaster extremely well. The success indicators included a SMART triage, autopsy and tagging/labeling dead bodies, public notification system, effective hospital networking for patient transfer and getting injured family members together, excellent media management, important dignitaries' management, important decision-making processes, and commendable teamwork. The critical aspects of management proved as a key indicator for the successful management.
The paper discusses the details of the case study and analyzes each indicator in greater focus. The lessons learned are critically evaluated.

Prehosp Disaster Med 2011;26(Suppl. 1):s60

doi:10.1017/S1049023X1100207X

\section{(A219) Development of a Hospital Disaster Plan for Countries with Limited Resources \\ F. Plani}

Trauma Unit, Department of Surgery, Johannesburg, South Africa

The Chris Hani Baragwanath Hospital (CHBH) in South Africa is the largest in the world, with 2,900 beds. Its trauma unit boasts 15 resuscitation bays, while the triage area has space for 40 stretchers. There are 5,000 trauma resuscitations performed yearly, out of 50,000 patients seen in the Trauma Emergency Department. There is an eight-bed Trauma Intensive Care Unit (ICU) and a 56-bed Trauma Ward. There also are 25 stepdown beds, 70 outlying beds, a six-bed Burn ICU, 20-bed ward, and a 24-bed shortstay ward. There are about 80 resuscitations and 70 trauma emergency operations weekly. However, the hospital is severely limited in financial and human resources, with only 2-3 interns, two registrars, and one trauma consultant on-call. The hospital is at $>130 \%$ bed occupancy. The CHBH was designated as the main disaster hospital for the 2010 FIFA World Cup, due to its proximity to the 96,000 -seat Soccer City. Nominal disaster plans existed, but there were no resources, preparations, or knowledge, as was the case with most other government hospitals. The Trauma Directorate developed a new plan for the World Cup, future mass-casualty incidents at $\mathrm{CHBH}$, and for other resource limited hospitals. The plans are centered on four critical issues: (1) preparedness of hospital structure and staff; (2) dissemination of the plan; (3) disaster training; and (4) the development of "Disaster Bags" for 350 casualties A free disaster course trained $>400$ staff members on in-hospital triage and trauma management. All hospital staff were allocated specific functions in case of disasters. This is the first time the $\mathrm{CHBH}$ has had an integrated disaster plan, with separate equipment allocation, through private funding, and involving all disciplines.

Prehosp Disaster Med 2011;26(Suppl. 1):s60

doi:10.1017/S1049023X11002093

(A221) Medical Preparedness for Expo 2010 Shanghai China

Z. Liu

Trauma \& Emergency Center, Shanghai, China

Objective: EXPO 2010 Shanghai China attracted about 246 nations and international organizations as well as 73 million visitors from home and abroad. To provide good medical services to is a challenge.

Methods: Eight Level A hospitals are designated as EXPO Hospitals to provide advanced medical services to those who need critical care. There are five first aid stations in the EXPO park to provide first aid to EXPO visitors and staff. First aid at scene and emergency response are the emphasis. Practical, realistic, and systematic and forewarning emergency plans are made. An agile and efficient structure is organized. All EXPO 
staff members underwent first aid training, especially the CPR training and the use of AED. The public are trained for self rescue skills via different approaches and provided with first-aid kits. A medical rescue team is recruited; the team consists of Critical Care physicians, surgeons, anesthetists and nurses. The team is able to deal with different situations under all conditions. The team is a standing army, after the EXPO, the team will be responsible for providing medical services in the regional disaster rescue. Drills are performed periodically to practice the rescue skills, enhance the communication and cooperation among different government departments.

Results: By joint efforts, a safe, wonderful and unforgettable EXPO was presented to the world. During the 184 days, medical personnel provided medical services to the 73 million visitors.

Conclusions: The medical preparedness for World EXPO should be practical, realistic, and systematic and forewarning. The public should have the easy access to the information and resources. Develop the contingency plans according to the real situation, ensure its timely updating and deliver training to every one involved. Drills should be performed periodically to practice the rescue skills, enhance the communication and cooperation among different government departments.

Prehosp Disaster Med 2011;26(Suppl. 1):s60-s61

doi:10.1017/S1049023X1100210X

(A225) Lessons Learned at the Commonwealth Games: A Mass-Gathering Sporting Event in New Delhi, India A. Madan

Jamsetji Tata Centre of Disaster Management, mumbai, INDIA

Mass gatherings can be religious, political, socio-cultural, or sporting events, and vary in the form of processions, car races, conferences, fairs, etc. New Delhi hosted the 2010 Commonwealth Games, a mass gathering spread over a duration of 10 days with different venues and a high density of participants, spectators, security personnel, volunteers, and high-profile guests. Various organizations were involved in the planning and implementation of the games which called for a collaborative and coordinated effort to make the event a success. Security coverage was required for 23 sporting, 32 training, and seven non-sporting venues. Security arrangements were of utmost importance and required training, mobilization, and deployment of army, police, and other emergency workers, as well as establishing Standard Operating Procedures for responses to chemical, biological, radioactive, and nuclear events and availing specialized equipment. Areas of public health interventions in mass gathering include mass-casualty preparedness, disease surveillance and outbreak response, safety of water, food, and venues, health promotion, public health preparedness and response, pest and vector control, coordination and communication, healthcare facility capacity, and medical supplies. Methods adopted for the study included interviews with the stakeholders of the Commonwealth Games and use of secondary data to cite examples and support arguments. Existing knowledge must be documented and made available for use in planning for future mass gatherings. The size, duration, and interest of such events demands special attention toward preparedness and mitigation strategies to prevent or minimize the risk of ill health and maximizing the safety of people involved.

Prehosp Disaster Med 2011;26(Suppl. 1):s61

doi:10.1017/S1049023X11002111

(A226) Establishing a Framework for Synchronizing Critical Decision Making with Information Analysis during a Health/Medical Emergency

J. Paturas, J. Pelazza, R. Smith

Center For Emergency Preparedness And Disaster Response, New Haven, United States of America

Background: The Yale New Haven Center for Emergency Preparedness and Disaster Response (YNH-CEPDR) has worked in the United States with state and local health and medical organizations to evaluate critical decision making activities and to develop decision making tools and protocols to enhance decision making in a time sensitive environment. YNH-CEPDR has also worked with international organizations and US federal agencies to support situational awareness activities in simulated and real world events.

Objectives: During this session YNH-CEPDR will share the best practices from recent events such as the H1N1 response and the Haiti Earthquake. Participants will be engaged in discussions regarding overall framework for successful information collection, analysis and dissemination to support decision making based on these experiences. This session will also incorporate concepts provided by the US National Incident Management System (NIMS) and the Incident Command System (ICS), specifically through the development of Situational Reports (SitReps), Incident Action Plans (IAP) and Job Action Sheets as methods to implement the framework and concepts discussed. Participants will be led through a series of scenario-based discussions to allow application of critical decision making factors to their organization. At the conclusion of the session, participants will be able to identify next steps for enhancing the synchronization of critical decision making and information analysis within their organizations.

Prehosp Disaster Med 2011;26(Suppl. 1):s61

doi:10.1017/S1049023X11002123

(A227) Tension between Emergency Management Policy Decisions and Aged Care Facilities in Australia: A Case Study

L. Cusack, L. Siegloff, P. Arbon, A. Hutton, L. Mayner

Flinders University Research Centre for Disaster Resilience and Health, Adelaide, Australia

This paper considers the impact that a number of Australian emergency management policy and operational decisions are having on residential aged care facilities located in the community. For example, all residential aged care facilities applying for new federal government funded aged care places are required to demonstrate a plan for environmental disaster threats such as bushfires and floods. Another example is the adoption of new fire danger rating scale, with the inclusion of an extreme level called "catastrophic"-code red. This inclusion requires all services and community members, living in bushfire-prone areas to decide whether or not to evacuate the day before or morning of a Bureau of Meteorology fire danger index indicating a code 